\title{
Epidemiological, Clinical and Therapeutic Characteristics of Hypertensive Type 2 Diabetics at the Marc Sankale Center of Dakar
}

\author{
Djiby Sow ${ }^{1 *}$, Demba Diédhiou ${ }^{1}$, Ibrahima Mané Diallo', Amadou Ndiaye ${ }^{2}$, Michel Assane Ndour ${ }^{1}$, \\ Anna Sarr ${ }^{1}$, Saïd Norou Diop', Maimouna Ndour-Mbaye ${ }^{1}$ \\ ${ }^{1}$ Department of Internal Medicine II, University Hospital Center of Dakar, Cheikh Anta Diop University, \\ Dakar, Senegal \\ ${ }^{2}$ Laboratory Analyzes Medical Biology, Abass NDAO Hospital in Dakar, Dakar, Senegal \\ Email: ^drdjiby@yahoo.fr, dembadiedhiou1976@gmail.com, ibrahimamanediallo@hotmail.fr, drndiayeamadou1@yahoo.fr, \\ michelassanendour@yahoo.fr
}

How to cite this paper: Sow, D., Diédhiou, D., Diallo, I.M., Ndiaye, A., Ndour, M.A., Sarr, A., Diop, S.N. and Ndour-Mbaye, M. (2018) Epidemiological, Clinical and Therapeutic Characteristics of Hypertensive Type 2 Diabetics at the Marc Sankale Center of Dakar. Open Journal of Endocrine and Metabolic Diseases, 8, 59-69. https://doi.org/10.4236/ojemd.2018.82007

Received: November 21, 2017

Accepted: January 22, 2018

Published: January 25, 2018

Copyright (C) 2018 by authors and Scientific Research Publishing Inc. This work is licensed under the Creative Commons Attribution International License (CC BY 4.0).

http://creativecommons.org/licenses/by/4.0/

Open Access

\begin{abstract}
Introduction: High blood pressure (hypertension) and diabetes mellitus are two major risk factors for cardiovascular disease, which is increasing rapidly in Africa and worldwide. Africa has the highest prevalence rate of hypertension in the world, with $46 \%$ of adults over the age of 25 with. Hypertension is common in type 2 diabetes and increases cardiovascular risk. The association of these two pathologies has many particularities in the sub-Saharan subject. The work related to this entity in Africa shows a frequency between $30 \%$ and $60 \%$. The objective was to describe the epidemiological, clinical and therapeutic characteristics at the Medical Clinic II of the Abass Ndao Hospital Center in Dakar. Patients Methods: This was a cross-sectional, descriptive and analytical study conducted from 01 December 2016 to 31 January 2017. It focused on patients with cardiothyrosis. Epidemiological data, cardiovascular risk factors, and cardiothoracic characteristics were evaluated. Results: 303 cases were recorded with a prevalence of $42 \%$, an average age of 61.63 years, a sex ratio of 0.22 . The age group of [60 - 70] years was the most representative at $36.30 \%$. The BMI (Body Mass Index) average was $27.06 \mathrm{~kg} / \mathrm{m}^{2}$. Obesity was $25 \%$ and $35 \%$ were overweight. Dyslipidemia consisting of an increase in LDL cholesterol $>1 \mathrm{~g} / \mathrm{l}$ in 79\%, a hypercholesterolemia in 57\%, a decrease in HDL cholesterol in $13.23 \%$ and a hypertriglyceridemia in $28 \%$. Patients with three cardiovascular risk factors accounted for $93.72 \%$. The average fasting glucose level was $2.85 \mathrm{~g} / \mathrm{l}$. Hyperglycemia was noted in $65 \%$. The glycosylated hemoglobin is greater than $7 \%$ in $47 \%$. The duration of diabetes was less than 5 years
\end{abstract}


in 133 patients or $44 \%$. $70 \%$ of patients were treated with oral antidiabetic drugs. Insulin was used in $21.1 \%$. Hypertension was mild in $24.1 \%$, moderate in $23.8 \%$ and severe in $14.8 \%$. Hypertension treated with monotherapy was $49 \%$, combination therapy was $43 \%$. Converting enzyme inhibitors (CEI) were used in 44\%; 20\% were Calcium inhibitors and 7 were treated by Angiotensin II Receptor Antagonists (ARA). The inhibitor association of the conversion enzyme/calcium inhibitors (CEI/CI) is in $22 \%$. Statins are used in $23 \%$. The degenerative complications concerned four cases of acute edemas of the lower limbs (AELL), four cases of stroke (AVC). 37\% had a balance of the blood pressure and among them $19.5 \%$ had followed a monotherapy and $33 \%$ a combination therapy. Conclusion: The combination of hypertension and diabetes is common in Africa and increases cardiovascular mortality. Training in the management of diabetes and other cardiovascular risk factors is needed.

\section{Keywords}

Diabetes, Hypertension, Risk Factors, Treatment, Senegal

\section{Introduction}

High blood pressure (hypertension) and diabetes mellitus are two major risk factors for cardiovascular disease, which is increasing rapidly in Africa and worldwide [1] [2]. Africa has the highest prevalence rate of hypertension in the world, with $46 \%$ of adults over the age of 25 with [3]. Hypertension doubles the risk of mortality and stroke at any case; it triples the risk of coronary heart disease and accelerates the progression of diabetic nephropathy, retinopathy, and neuropathy [3]. As such, early and adequate treatment is necessary to delay these complications. Indeed, some studies exist in Africa on the association of diabetes mellitus and hypertension. According to what we know about, no study has been done so far on the combination of these two risk factors in Dakar. Hypertension is common in type 2 diabetes and increases cardiovascular risk. The association of these two pathologies has many particularities in the sub-Saharan subject.

In this way the objective of this study is to describe the epidemiological, clinical and therapeutic aspects of type 2 hypertensive diabetes at the Medical Clinic II of the Abass Ndao Hospital Center in Dakar.

\section{Patients and Methods}

It was a cross-sectional, descriptive and analytical study conducted from December 15, 2016 to January 15, 2017, for a duration of 1 month. The study was carried out at the Marc Sankale Center of the Abass Ndao Hospital Center in Dakar. This center has been the national reference center for the management of diabetes and metabolic endocrine diseases in Senegal since 1960. The study included all hypertensive type 2 diabetes patients followed in the department and having a medical record. We considered as hypertensive patients those who were 
already there and followed with antihypertensive treatment. A pre-established form was used as a basis for data collection. It focused on the following elements:

- Socio professional data: age, sex, profession; ethnicity and address.

- The antecedents and risk factors associated.

- Family history (in first-degree relatives) and personal history (medico-surgical and gynecological-obstetrical). Habits and lifestyles such as smoking, alcoholism and sedentary lifestyle.

- The study of diabetes mellitus: type of diabetes, its seniority, its treatment, complications.

Para clinical assessment: Fasting blood glucose, Hbalc, renal function and micro albuminuria, electrocardiogram (ECG), fundus.

- A review of cardiovascular risk factors.

Those considered in this study, since all patients are diabetic, were: age ( $>55$ years in men and 60 years in women), active smoking, sedentary lifestyle, blood pressure over $130 \mathrm{~mm} \cdot \mathrm{Hg}$, obesity, dyslipidemia, microalbuminuria greater than $30 \mathrm{mg} / 24 \mathrm{~h}$, hypercholesterolemia $>2 \mathrm{~g} / \mathrm{l}$, HDL down $<0.35 \mathrm{~g} / \mathrm{l}$, hypertriglyceridemia $>1.5 \mathrm{~g} / \mathrm{l}$. The lipid balance was performed during a checkup.

- The treatment: low sodium diet, drug treatment of diabetes and treatment of high blood pressure, platelet and antiplatelet therapy statins.

- Diagnosis and glycemic balance.

The types of diabetes, in the absence of immunology and the peptide $\mathrm{C}$ assay, were presumptive based on the clinical and evolutionary arguments (age of the patient, its morph type, time of installation of the symptoms, family history and evolution under treatment).

Patients were in glycemic equilibrium if the fasting blood glucose was less than $1.08 \mathrm{~g} / 1$ according to IDF [4] and less than $1.21 \mathrm{~g} / \mathrm{l}$ according to ADA [5]. $\mathrm{Hba} 1 \mathrm{C}$ is less than $6.5 \%$ according to IDF and below $7 \%$ according to the ADA [4].

- Hypertension.

- Definition of the Arterial Hypertension: It is a blood pressure $\geq 140$ and/or $90 \mathrm{~mm} \cdot \mathrm{Hg}$.

- Classification of the Arterial Hypertension.

The classification is based, if the PAS and the PAD belong to distinct categories, the highest stage is retained. WHO (World Health Organization) 1999 classification by level of AP (cuff). The Table 1 shows the classification of hypertension according the World Health organization (WHO).

Balance of the Arterial Hypertension was judged if the BP was below 140/90 $\mathrm{mm} \cdot \mathrm{Hg}$.

- Obesity: We also used the International Obesity Task Force classification to classify patients according to the body mass index [7]. Normal values are 18.5 to $24.9 \mathrm{~kg} / \mathrm{m}^{2}$. Overweight is reported when $24.9<\mathrm{BMI}<30 \mathrm{~kg} / \mathrm{m}^{2}$ and obesity when BMI $>29.9 \mathrm{~kg} / \mathrm{m}^{2}$ [8] [9]. 
Table 1. WHO (World Health Organization) classification of hypertension [6].

\begin{tabular}{ccc}
\hline Category & PAS $(\mathrm{mm} \cdot \mathrm{Hg})$ & PAD $(\mathrm{mm} \cdot \mathrm{Hg})$ \\
\hline Optimal & $<120$ & $<80$ \\
Normal & $120-129$ & $80-84$ \\
Normal High & $130-139$ & $85-89$ \\
Grade 1 Light & $140-159$ & $90-99$ \\
Grade 2 Moderate & $160-179$ & $100-109$ \\
Grade 3 Severe & $\geq 180$ & $\geq 110$ \\
Systolic Hypertension & $\geq 140$ & $<90$ \\
\hline
\end{tabular}

\subsection{Inclusion and Exclusion Criteria}

Any previously known hypertensive patient followed at the center was considered in the study. Excluded unknown hypertensive patients or patients not taking antihypertensive drugs at the time of the study. Incompletely clinical and or paraclinical records were not included in the final evaluation.

\subsection{Statistical Analysis}

We did a prospective study and the data were entered on an Excel sheet and the qualitative and quantitative variables were analyzed by the SPSS STATISTICS 18.0 software.

\section{Results}

\section{1) Epidemiological aspects}

During the study period, we recorded 723 diabetic patients at the Marc Sankale center of Abass Ndao hospital in Dakar. Among them there were 303 hypertensive diabetics with a hospital frequency of $42 \%$. There were 249 women $(82.18 \%)$ and 54 men $(17.82 \%)$ with a sex ratio $(\mathrm{M} / \mathrm{W})$ of 0.22 . The average age was 61.63 years with extreme from 31 years old to 92 years old. The age group of [60 - 70] years was the most representative with $\mathrm{n}=110 \%$ or $36.30 \%$.

Urban patients were the most representative with a rate of $93 \%$ and $2 \%$ were of rural origin.

In our population, the Wolof, Pulars and Serer were the most represented with respectively $44 \%, 18 \%$ and $12 \%$. Housewives accounted for $39 \%$ of cases. The Table 2 shows the distribution of Patients by Sociodemographic Characteristics.

\section{2) Study of risk factors}

The BMI average is $27.06 \mathrm{~kg} / \mathrm{m}^{2}$ with extremes of 16.36 to $41.47 \mathrm{~kg} / \mathrm{m}^{2}$. Obesity was $25 \%$ and $35 \%$ were overweight. The dyslipidemia was observed in our sample. It was an increase in LDL cholesterol $>1 \mathrm{~g} / \mathrm{l}$ in $79 \%$, an increase in total cholesterol $>2 \mathrm{~g} / \mathrm{l}$ in $57 \%$, a decrease in HDL cholesterol $<0.40 \mathrm{~g} / \mathrm{l}$ in $13.23 \%$ and an increase of triglycerides greater than $1.5 \mathrm{~g} / \mathrm{l}$ to $28 \%$. In our study, patients with three cardiovascular risk factors accounted for $93.72 \%$. The Table 3 shows the distribution of patients by number of risk factors. 
Table 2. Distribution of patients by sociodemographic characteristics.

\begin{tabular}{cc}
\hline \multicolumn{2}{c}{ Characteristics of Patients in Inclusion $(\mathbf{n}=\mathbf{3 0 3})$} \\
\hline Average age & 61.63 years \\
Age $\geq \mathbf{6 0}$ years & $49.1 \%$ \\
Women & $249(82.18 \%)$ \\
Sex ratio (M:F) & 0.22 \\
Urban patients & $93 \%$ \\
Housewives & $39 \%$ \\
The age group [60 - 69] years & $110(36.3 \%)$ \\
Average age of diabetes & 10.3 year \\
Treatment OAD & $(212) 70 \%$ \\
Glycosylated hemoglobin > 7\% & $144(44 \%)$ \\
Hypertension severe & $14.8 \%$ \\
Combination therapy & $43 \%$ \\
\hline
\end{tabular}

Table 3. Distribution of patients by number of risk factors.

\begin{tabular}{lc}
\hline $\mathbf{1}$ risk factor & $1 \%$ \\
2 risk factor & $6 \%$ \\
3 risk factor & $20 \%$ \\
4 risk factor & $39 \%$ \\
$\mathbf{5}$ risk factor & $20 \%$ \\
$\mathbf{6}$ risk factor & $14 \%$ \\
Total & $100 \%$ \\
\hline
\end{tabular}

\section{3) Diabetes study}

The average fasting glucose level was $2.85 \mathrm{~g} / \mathrm{l}$. A hyperglycemia was noted in $65 \%$ of the population. The glycosylated hemoglobin greater than or equal to $7 \%$ in 144 patients is $47 \%$. The duration of diabetes was less than 5 years in 133 cases is $44 \%$, between 5 to 10 years in 62 cases (20\%), diabetes has been evolving for more than ten years in $33 \%$. In our study (212) patients or $70 \%$ were treated with oral anti diabetic drugs (OAD). Insulin alone was used in $21.1 \%$.

\section{4) Study of hypertension}

Blood pressure was normal in 113 cases or $37.3 \%$. Hypertension was mild in 73 cases or $24.1 \%$, moderate in 72 cases $(23.8 \%)$ and severe in 45 cases (14.8\%). The treatment of hypertension in our patients was monotherapy of $49 \%$ or 148 cases, one hundred and twenty-nine patients (129) were on combination therapy or $43 \%$; only twenty-six patients (26) had a HAART consisting solely of women. CEI were used in 65 patients (44\%). Twenty-nine (29) cases or $20 \%$ were on calcium inhibitors. Ten (10) patients or 7\% were treated with Angiotensin II Receptor Antagonists (ARA). Thiazide diuretics were used in 30 patients $(20 \%)$ and cardiac beta blockers (CBB) in 14 cases (9\%). Two types of combination were noted in dual therapy: the inhibitor association of the conversion enzyme/calcium inhibitors.

(IEC/CI) 28 patients or $22 \%$ and IEC/IUD association in 101 patients (78\%). For triple therapy (HAART) three types of combination were noted in our study: 
IEC/IUD/CI in ten patients $38.6 \%$.

- IEC/IUD/CBB in eight patients $30.7 \%$ and IEC/CBB/CI in eight patients $30.7 \%$.

Only (164) patients or 54\% had a balance of blood pressure. Among these balanced patients, fifty-nine (59) patients or $19.5 \%$ had followed monotherapy, one hundred and one (101) patients or $33 \%$ had followed a combination therapy and four people were balanced by following a HAART or $1 \%$. Of the 59 individuals who were balanced as monotherapy, six (6) were on ARA II, twenty-six (26) had normal blood pressure on ACE, nine (9) were on CBB, five had balance of tension under CI and thirteen (13) patients were under IUDs. In combination therapy (101) patients treated with IEC/IUD had normal blood pressure with sixty (28) patients treated with IEC/CI. In HAART, four patients treated with IEC/IUD/CBB showed normal tension .The lipid-lowering drugs used were statins with a $23 \%$ rate.

\section{5) Study of complications}

The degenerative complications noted were four cases of acute edemas of the lower limbs (AELL), four cases of stroke, one case of myocardial infarction (MI) and three cases of renal failure. The fundus examination was performed in only forty-eight (48) patients. Of these five (1.65\%) had progressive diabetic retinopathy, one patient $(0.33 \%)$ had hypertensive retinopathy.

\section{Discussion}

\section{Methodology}

Our study knows certain limits. The collection of data was not exhaustive in clinical and paraclinical terms. Some additional tests were not performed in all patients because of their excessive cost in the center. All the variables studied had a satisfactory level of completeness with $95 \%$ of the variables reported.

\section{1) Epidemiological aspects}

During the study period, hypertensive diabetics accounted for a hospital frequency of $42 \%$. This rate agrees with data from literature who estimated that Hypertension is common in patients with diabetes in Africa with rates ranging from $20 \%$ to $60 \%$ depending on the region [10]. Formerly H. Monabeka [11] in a study in the Congo found a frequency of $11.71 \%$. Indeed, hypertension and diabetes mellitus are increasing rapidly in Africa and in the world [12] [13]. Several authors reported a few years ago 65\% hypertensive subjects in people with diabetes [10] [14]. Recent multicenter data reported a prevalence of hypertension of up to $77 \%-81 \%$ during T2DM in Africa [14] [15].

The average age was 61.63 years old with a female predominance. As in other series, the frequency of the diabetes-hypertensive association increases with age, particularly in the age group of 50 to 60 years and predominates in the female sex [16] [17]. In our series the age group of [60 - 70] years was the most representative with $36.30 \%$.

2) Study of risk factors 
Obesity was $25 \%$ and $35 \%$ were overweight. Overweight remains a determining factor in the occurrence of hypertension, diabetes and their complications at the individual level [18].

The dyslipidemia was observed in our sample. Atherogenic lipid profile is usually observed in diabetic patients; a Japanese study found a positive correlation between blood pressure and HDL down in diabetic hypertensive patients over the age of 50 [19]. In our study, HDL down emitted was observed in $13.23 \%$ of cases and LDL-c was greater than $1 \mathrm{~g} / \mathrm{l}$ in $79 \%$ of cases an increase in total cholesterol $>2 \mathrm{~g} / \mathrm{l}$ in $57 \%$. Dyslipidemia associated to diabetes and hypertension constitutes a metabolic syndrome. It is a major risk factor for the occurrence of cardiovascular events; its correction, in particular by statins, makes it possible to reduce cardiovascular morbidity and mortality in type 2 diabetes, up to $37 \%$ compared to placebo, as observed in the CADS study (Collaborative Atorvastatin Diabetes Study) [20] [21]. Diabetics should be sensitized to this risk for a better adherence to the prescription of the lipid balance. However, it should be emphasized that prescribers should be more benefit so that lipid exploration is systematic for all diabetics including hypertensive diabetics.

In our study, patients which three cardiovascular risk factors accounted and over accounted for $93.72 \%$. The hypertensive associated to Type 2 diabetes increases the cardiovascular risk of the patients, through a synergistic effect [22], it is responsible for an important global and cardiovascular morbid mortality [23].

\section{3) Diabetes study}

The glycosylated hemoglobin greater than or equal to $7 \%$ in 144 patients or $47 \%$. In our study, the evaluation of the glycemic balance is based on fasting glucose and glycosylated hemoglobin (Hbalc). The latter is important for the monitoring and evaluation of diabetes [24]. Efforts must be made to make it available and at a lower cost in the decentralized structures. A poor glycemic balance was noted in $65 \%$ of the population. This requires strengthening therapeutic education to improve the glycemic balance. In our study $70 \%$ were treated with oral antidiabetic drugs (OAD).

\section{4) Study of hypertension}

Thus, its management takes first and foremost a good control of blood pressure figures. However, beyond the problems of treatment compliance generated by the multiplication of drug intake, there is the essential question of how to determine the various parameters defining the normality of blood pressure figures [25]. In fact, although the clinical assessment of AP in the medical office is the basis of the recommendations of the French Society of Hypertension (FSH) [26], it is insufficient in certain circumstances and can lead to inadequate and/or inappropriate or even unnecessary treatment [25] [26]. MAPA may therefore appear as an effective means and may reveal hidden HTAs.

The treatment of hypertension of our patients was monotherapy of $49 \%$, a combination therapy in $43 \%$. Only twenty-six patients (26) had HAART. For Monabeka [11] in his study $93 \%$ of patients were on monotherapy.

ACE inhibitors were used in $44 \%, 20 \%$ were on calcium inhibitors and $7 \%$ 
were treated with angiotensin II receptor antagonists (ARA). The lipid-lowering drugs used were statins with $23 \%$.

In our study blood pressure was controlled in $37.3 \%$ of patients. This result is in accordance with African literature. Thus, most of African studies report a poor blood pressure control, ranging from $10 \%$ to $37 \%$ despite the high number of molecules often used. For example, in Dembélé study in Mali involving 112 patients, almost half of the subjects were not well controlled under dual therapy [9], or Adeniyi et al., in South Africa who reported 76\% of uncontrolled subjects while nearly three quarters of them were on triple therapy [27]. This rate is similar to the study, conducted in Portugal, and showed that only $40 \%$ of treated hypertensive patients with diabetes are really controlled [28]. A prospective study, conducted in Tunisia on 300 known and treated hypertensive patients type 2 diabetes (DT2), showed that only $23.3 \%$ of patients are really controlled on a blood pressure level [29]. This insufficiency of blood pressure control can be explained, by the observance estimated at only $15 \%$, itself favored by the excessive costs of treatment and the complex care pathways [27].

\section{5) Study of complications}

The degenerative complications noted were four cases of acute edemas of the lower limbs (AELL), four cases of stroke, one case of myocardial infarction (MI) and three cases of renal failure. The prevalence of stroke (1.32\%) is consistent with that found in Algeria (2.4\%) and France (1.7\%) Belhadj et al. found in Algeria, $8.5 \%$ of arteriopathy of the lower limbs [30]. In France Bringer and al. found in 2008 a prevalence of 5.9\% [31]. This low prevalence may have material reasons, some patients could pay, in addition to their treatment, came analysis biological fees.

The United Kingdom prospective diabetes study (UKPDS) has shown a linear relationship between systolic blood pressure control and the decrease in micro and macro vascular complications [32] [33]. The Action in Diabetes and Vascular Disease study: preterax and Diamicron MR Controlled Evaluation (ADVANCE) confirmed these data [34].

\section{Conclusion}

The combination of hypertension and diabetes is common in Africa and increases cardiovascular mortality. Training in the management of diabetes and other cardiovascular risk factors is needed. Other similar studies should flesh out these preliminary results.

\section{References}

[1] Arguedas, J.A., Leiva, V. and Wright, J.M. (2013) Blood Pressure Targets for Hypertension in People with Diabetes Mellitus. Cochrane Database of Systematic Reviews, 2013, Article ID: CD008277. https://doi.org/10.1002/14651858.CD008277.pub2

[2] Hypertension in Diabetes Study Group (1993) HDS I: Prevalence of Hypertension in Newly Presenting Type 2 Diabetic Patients and the Association with Risk Factors for Cardio-Vascular and Diabetic Complications. Journal of Hypertension, 11, 309-317. 
https://doi.org/10.1097/00004872-199303000-00012

[3] Sowers, J.R., Epstein, M. and Frohlich, E.D. (2001) Diabetes, Hypertension, and Cardiovascular Disease: An Update. Hypertension, 37, 1053-1059.

https://doi.org/10.1161/01.HYP.37.4.1053

[4] International Diabetes Federation (2013) IDF Diabetes Atlas. 5th Edition, IDF, Brussels.

[5] American Diabetes Association (ADA) (2008) Medical Management of Hyperglycemia in Type 2 Diabetes: A Consensus Algorithm for the Initiation and Adjustment of Therapy. Diabetes Care, 31, S1-S11.

[6] World Health Organization (WHO) (2003) International Society of Hypertension (ISH) Statement on Management of Hypertension. Journal of Hypertension, 21, 1983-1992. https://doi.org/10.1097/00004872-200311000-00002

[7] Cole, T.J., Bellizzi, T.M., Flegal, M.E. and Dietz, W.H. (2000) Establishing a Standard Definition for Overweight and Obesity Worldwide. BMJ, 320, 1240-1243. https://doi.org/10.1136/bmj.320.7244.1240

[8] Buysschaert, M. (2001) Clinical Diabetology. Ed De Boeck University, Brussels, 71-83.

[9] Dembele, M., Sidibe, A.T., Traore, H.A., et al. (2000) Association HTA-Diabetes Mellitus in the Internal Medicine Department of the "G" Point Hospital Bamako. Black African Medicine, 47, 276-278.

[10] Chukem, S.P., Kengne, A.P., Dehayem, Y.M., et al. (2007) Hypertension in People with Diabetes in Sub-Saharan Africa: Revealing the Hidden Face of the Iceberg. Diabetes Research and Clinical Practice, 77, 293-299.

https://doi.org/10.1016/j.diabres.2006.11.007

[11] Monabeka, H. (1998) Arterial Hypertension and Diabetes Sugar about 152 Diabetics. Hypertends Medicine of Black Africa, 45, 105-109.

[12] Arguedas, J.A., Leiva, V. and Wright, J.M. (2013) Blood Pressure Targets for Hypertension in People with Diabetes Mellitus. The Cochrane Database of Systematic Reviews, No. 10, CD008277. https://doi.org/10.1002/14651858.CD008277.pub2

[13] Tankeu, A.T. and Noubiap, J. (2016) Oscillating Blood Pressure Therapeutic Target in Type 2 Diabetes Patients with Hypertension. Annals of Translational Medicine, 4, 422. https://doi.org/10.21037/atm.2016.11.16

[14] Sobngwi, E., Ndour-Mbaye, M., Boateng, K.A., et al. (2012) Type 2 Diabetes Control and Complications in Specialized Diabetes Care Centers of Six Sub-Saharan African Countries: The Diabcare Africa Study. Diabetes Research and Clinical Practice, 95, 30-36. https://doi.org/10.1016/j.diabres.2011.10.018

[15] Ogola, E. (2016) High Prevalence and Poor Control of Hypertension and Associated Cardiovascular Risk Factors in Diabetic Patients in a Rural Hospital in Kenya. Journal of Hypertension, 34.

[16] Bruckert, F., Hieronimos, S., Gerbet, C., Fenichel, P., Strulo, S. and Harter, M. (1990) Epidemiological Study of Arterial Hypertension and Its Complications in a Population of 109 Hospitalized Diabetics. Medecine Et Hygiene, 48, 1681-1685.

[17] Grimaldi, A., Coutarel, P., Bousquet, F. and Sachon, C. (1989) Hypertension and Diabetes. Medical Competition, 32, 2727-2736.

[18] Cambian, F. (1982) Relationship between Excess Weight and Arterial Hypertension. La Presse Médicale, 11, 3641-3646.

[19] Taeko, M. (2002) HDL Cholesterol, But Not to Hyperlipidemia in Hypertensive Pa- 
tients Aged 50 Years or Older. Hypertension Research, 25, 335-341.

[20] Meigs, J.B., Rutter, M.K., Sullivan, L.M., Fox, C.S., Agostino, R.B. and Wilson, P.W. (2007) Impact of Insulin Resistance on Type 2 Diabetes and Cardiovascular Disease in People with Metabolic Syndrome. Diabetes Care, 30, 1219-1225. https://doi.org/10.2337/dc06-2484

[21] Charlton-Menys, V., Betteridge, D.J., Colhoun, H., Fuller, J., France, M., Hitman, G.A., Livingstone, S.J., Neil, H.A., Newman, C.B., Szarek, M., DeMicco, D.A. and Durrington, P.N. (2009) Apolipoproteins, Cardiovascular Risk and Statin Response in Type 2 Diabetes: The Collaborative Atorvastatin Diabetes Study (CARDS). Diabetologia, 52, 218-225. https://doi.org/10.1007/s00125-008-1176-8

[22] Klein, R. (1995) Hyperglycemia and Microvascular and Macrovascular Disease in Diabetes. Diabetes Care, 18, 258-268. https://doi.org/10.2337/diacare.18.2.258

[23] United Kingdom Prospective Diabetes Study Group (1998) UK Prospective Diabetes Study 23: Risk Factors for Coronary Artery Disease in Non-Insulin Dependent Diabetes. BMJ, 316, 823-828. https://doi.org/10.1136/bmj.316.7134.823

[24] Nathan, D.M., Hawk, J.B., Davidson, M.B., et al. (2009) Medical Management of Hyperglycaemia in Type 2 Diabetes Mellitus: A Consensus Algorithm for the Initiation and Adjustment of Therapy: A Consensus Statement from the American Diabetes Association and the European Association for the Study of Diabetes. Diabetologia, 52, 17-30. https://doi.org/10.1007/s00125-008-1157-y

[25] Bauduceau, B., Bordier, L., Dupuy, O. and Mayaudon, H. (2009) Ambulatory Measurement of Arterial Pressure (MAPA) in Diabetics. Metabolic Disease Medicine, 3 , 169-173.

[26] French Society of Hypertension (SFHTA) (2012) Blood Pressure Measurements. Recommendations of the French Society of Hypertension (SFHTA). Medicine of Metabolic Diseases, 6, 347-349.

[27] Adeniyi, O.V., Yogeswaran, P., Longo-Mbenza, B. and Ter Goon, D. (2016) Uncontrolled Hypertension and Its Determinants in Patients with Concomitant Type 2 Diabetes Mellitus (T2DM) in Rural South Africa. PLoS ONE, 11, e0150033. https://doi.org/10.1371/journal.pone.0150033

[28] Carmona, J., Amado, P., Vasconcelos, N., et al. (2004) Prognostic Markers in Treated Hypertensive Diabetic Patients. 28-Month Follow-Up. Revista Portuguesa de Cardiologia, 23, 1119-1135.

[29] Ben-Hamouda-Chihaoui, M., Kanoun, F., Ftouhi, B., et al. (2011) Assessment of Blood Pressure Balance by Ambulatory Measurement of Blood Pressure and Study of Factors Associated with Poor Blood Pressure Control in 300 Hypertensive Patients with Type 2 Diabetes. Annales De Cardiologie Et D' Angeiologie, 60, 71-76. https://doi.org/10.1016/j.ancard.2010.12.004

[30] Belhadj, M., Malek, R., Boudiba, A., et al. (2010) DiabCare Algeria. Metabolic Disease Medicine, 4, 88-92.

[31] Bringer, J., Fontaine, P., Detournay, B., et al. (2009) Prevalence of Diagnosis Type 2 Diabetes Mellitus in the General Population: The INSTANT Study. Diabetes \& Metabolism, 35, 25-31. https://doi.org/10.1016/j.diabet.2008.06.004

[32] Adler, A.I., Stratton, I.M., Neil, H.A., et al. (2000) Association of Systemic Blood Pressure with Macrovascular and Microvascular Complications of Type 2 Diabetes UKPDS 36, Prospective Observational Study. BMJ, 321, 412-419. https://doi.org/10.1136/bmj.321.7258.412

[33] Holman, R.R., Paul, S.K., Bethel, M.A., et al. (2008) 10-Year Follow-Up of Intensive Glucose Control in Type 2 Diabetes. The New England Journal of Medicine, 359, 
1577-1589. https://doi.org/10.1056/NEJMoa0806470

[34] Patel, A., et al. (2007) Effects of a Fixed Combination of Perindopril and Indapamide on Macrovascular and Microvascular Outcomes in Patients with Diabetes Mellitus (the ADVANCE Trial): A Randomized Controlled Trial. The Lancet, 370, 829-840. https://doi.org/10.1016/S0140-6736(07)61303-8 